\title{
Empirical Study on the Impact of Domestic Economic Cycle on Sichuan's Tourism
}

\author{
Junrong Liu, Qin Yan \\ School of Tourism and Management \& Economics, Leshan Normal University, Leshan, China. \\ Email: liujr@lsnu.edu.cn
}



\begin{abstract}
This article empirically enquires, from the perspective of demand, the impact of economic cyclical fluctuation on Sichuan tourism. The findings show that Sichuan tourism demand proves elastic to CPI, Sichuan's GNI capita and interest rate, and that CPI and interest rate fluctuations are negatively correlated with Sichuan domestic tourism demand, while, with which Sichuan's GNI capita is positively associated. The study also finds that per capita national income and the local consumer price index enjoy strong predictive power for Sichuan tourism.
\end{abstract}

Keywords: Economic Cycle; Sichuan Tourism; Impact

\section{Introduction}

Tourism fluctuations and regional tourism industry have long been extensively studied by scholars, but these studies rarely cover the long-term relationship between the economic cycle and tourism demand, and the studies on regional tourism hardly go beyond yearly qualitative evaluation. From the results of the literature review, the researches on the impact of macroeconomic fluctuation on China's regional tourism are uncommon yet. This article is dedicated to exploring the effect of economic cycle on the Sichuan tourism from demand perspective, which is of great significance for regional tourism policy making and circumventing tourism industrial risk.

\section{Review of the Literatures}

In most studies, the effect of economic cycle on demand in certain sectors is enquired through modeling a series of explanatory variables, and the majority of econometric models introduced the disposable income, interest rate, inflation rate or exchange rates which reflect the economic cycle fluctuation to interpret industrial demand fluctuation [1]. In some foreign literatures, some scholars also used the similar methods to study the interaction between macroeconomic fluctuations and the tourism industry [2-4]. Some commonly used explaining variables of the tourism demand can be found in the literatures of Crouch Meta-Analysis (1996) and the works of Witt (1995) and Lim (1997). Some researches show that tourism demand is elastic to economic cycle indicators. Wong's (1997) analyzed the impact of economic fluctua- tions on the tourism demand and found that the main economic cycle has a significant impact on tourism demand, based on economic variables such as price and disposable income. Gouveia and Rodrigues (2005), using non-parameter method by Harding and Pagan's (2003) and Hodrick-Prescott filtering method, investigated the synchronization between tourism cycle and economic cycle, and this groundbreaking study found that there is a stable lag between them. Andrea Guizzardi and Mario Mazzocchi (2010) using Harvey STS model (Structural Time Series Approach) studied the economic cycle's influence on the Italy tourism demand, and concluded that there is a lag effect on tourism demand from economic cycle and the impact of economic cycle on the tourism demand is effective.

\section{Theoretic Analysis}

Cyclical economic fluctuation is an objective reality and affects all socio-economic activities. Tourism economy as an important part of the tertiary industry is also unexceptionally haunted by the impact of macroeconomic volatility. From the demand perspective, domestic tourism is the major part of a country or regional tourism demand, and the main economic factors affecting travel demand are the travel motivation, affordability, leisure time, macro-political and macro-economic climates and the prices of tourism products, among which domestic per capita income, tax and price are the most direct impacting factors that the macroeconomic fluctuation mainly influence and thereby affects travel demand. 


\subsection{The Impact of National Income on Tourism Demand}

We hold that the income and leisure affect each other. When income increases, labor substitutes leisure. But once exceeding the critical point, leisure will replace labor [5]. With the volatility of the economy, wage income and asset income will fluctuate, thereby affecting people's affordability. Tourism consumption is mainly determined by household disposable income, but household disposable income is hardly independent from the level of income tax. Factually, the family income tax is of stability, and we set it as a constant, and to a large extent, the per capita income can represent the disposable income levels, so that it can partially determine the affordability of residents. According to some scholars, family income level currently determines the tourism consumption of a Chinese family, and income fluctuation will have the increasing marginal effects on travel demand [6].

\subsection{The Impact of Interest Rates on Tourism Demand}

Zheng Gu (1995) explored the impact of interest rates on tourism demand and found that interest rates and travel demand is negatively correlated. Substitution effect and income effect generated by fluctuations of interest rate have a significant impact on resident's tourism demand [3].

Firstly, changes in interest rates affect people's propensity to save, which help residents to make consumption costs minimized and the inter-temporal consumption utility maximized. In other words, the residents will adjust the proportion of consumption and savings in disposable income according to changes in interest rates. When interest rates increase, current consumption will decrease and savings rise, and future consumption increases. If the distribution of current and future consumption changes, people's travel affordability and travel demand will be directly affected.

Secondly, fluctuations in interest rates directly affect the residents' return on assets. Although China's capital market is not mature enough, but the fact that the majority of urban residents and the middle class invest in the stocks, funds, bonds and other capital goods is undeniable. In fact, majority of domestic tourists are urban or middle class residents. Therefore fluctuations in interest rates will have a significant impact on their non-wage income. Income effects and substitution effects generated by interest rates should be further strengthened and directly impact people's propensity to consume and thereupon affect the travel demand of residents.

\subsection{The Impact of Price on Tourism Demand}

The impact of price on demand is self-evident, and nearly all the economists reached a consensus that price negatively correlates with consumer demand ${ }^{1}$ [7]. Comparing with general merchandise, tourism products have uniqueness, monopoly or non-essential features, but in the situation of normal prices or national income, ${ }^{2}$ tourism goods are normal goods. Given other cases unchanged, the tourism demand of residents depends on the prices of tourism products [5].

\section{Empirical Analyses}

\subsection{Modeling}

Based theoretical analyses, we build following econometric model:

$$
\ln Y_{t}=a_{0}+a_{1} \ln P_{t}+a_{2} \ln I_{t}+a_{3} \ln R_{t}+\mu_{t}
$$

where $Y_{t}$ denotes the Sichuan domestic tourism income at time $t$, and $P_{t}$ is the price of the domestic tourism products at $t$, and $I_{t}$ is national per capita income at $t ; R_{t}$ denotes the real interest rate at $t$, and $\mu_{t}$ is the random error, and $a_{0}, a_{1}, a_{2}, a_{3}$ are parameters, and $a_{1}, a_{2}$ and $a_{3}$ are price elasticity, income elasticity and interest rate elasticity of $Y_{t}$.

\subsection{Data Description and Selection}

We have chosen Sichuan tourism income $\left(Y_{t}\right)$ and domestic tourist arrivals (annual average) to represent changes in the domestic tourism demand in Sichuan and China's per capita national income and real interest rates in China to reflect domestic economic fluctuations. Price fluctuation is indicated by the national consumer price index or the Sichuan Consumer Price Index. We select sample data for 1991 to 2010. Consumer price index and interest rates are collected from the national statistical yearbooks, and China's per capita national income comes from the official website of the World Bank.

In further indicator selection, we have the considerations as follows:

First, Sichuan Consumer Price Index has a high synchronization with the National consumer price index. For both reflect macroeconomic fluctuations and Sichuan tourism product prices, so I chose the former.

Second, we also found a high level of synchronization between Sichuan yearly tourism income and domestic yearly tourist arrivals, between which the correlation coefficient amounts over 0.9. For the unity of the data nature, we choose Sichuan domestic tourism income as the empirical sequence and discard the population of domestic yearly tourist arrivals.

Third, this paper employs, mainly based on rational consumer presumption, the real interest rate as one of the

\footnotetext{
${ }^{1}$ It is only true for normal goods herein.

${ }^{2}$ They herein refer to the income and prices in peaceful time without vicious competition, plague and natural disasters.
} 
explanatory variables, which is, because rational consumers make decisions based on real interest rates rather than the nominal interest rate in their inter-temporal consumption (Wang Liping, 2005).

Therefore, based on the theme of this paper, we set Sichuan domestic tourism income $\left(Y_{t}\right)$ as the dependent variable, and per capita income in China (ID $=I_{t}$ ), China's real interest rate (RD $\left.=R_{t}\right)$ and Sichuan consumer price index (CPID $\left.=P_{t}\right)$ as explanatory variables. All the empirical tests are conducted in Eviews 5.0 environment.

\subsection{Empirical Analyses Results}

\section{1) Regression Analysis}

For a long-term equilibrium analysis on effects of macroeconomic volatility over Sichuan domestic tourism demand, We employed the least squares method to make a regression test with Sichuan tourism demand $\left(\ln Y_{t}\right)$, per capita income $\left(\ln I_{t}\right)$, the real interest rate $\left(\ln R_{t}\right)$ and Sichuan Consumer price index $\left(\ln P_{t}\right)$, and results are as follows:

$$
\begin{gathered}
\ln Y_{t}=-1.512220666 \ln P_{t}+1.126388816 \ln I_{t} \\
-1.923482888 \ln R_{t}+7.175236834 \\
(-1.849962)(23.49877)(-2.796301)(1.873789)
\end{gathered}
$$

R-squared $=0.972470$;

Adjusted R-squared $=0.967309$;

$\mathrm{D}-\mathrm{W}$ stat $=2.231994$;

F-statistic = 188.3979;

Prob $($ F-statistic $)=0.00000$.

It can be seen from the above equation that the estimated regression coefficients $a_{2}, a_{3}$ are by $5 \%$ level T-test of significance, $a_{1}$ by $10 \%$ level. That is, all explanatory variables meet the test of significance. While, the equation F-test is also very significant, indicating that the model represent a strong linearity. Adjusted coefficient of determination $\left(\mathrm{R}^{2}\right), 0.967309$, implies the high level of model goodness of fit, and the D-W-stat value (2.231994) on the $1 \%$ significance level admits the nonexistence of first-order autocorrelation assumptions.

The regression coefficients inform that Sichuan Consumer Price Index $\left(P_{t}\right)$, China's real interest rate $\left(R_{t}\right)$ and travel demand $\left(Y_{t}\right)$ are negatively correlated. When Sichuan Consumer Price Index increases by $1 \%$, Sichuan tourism income decreases by more than $1.5 \%$. And when the domestic real interest rate increases by $1 \%$, the Sichuan tourism demand drops by $1.92 \%$. While, the per capita income and Sichuan tourism demand are positively correlated. With per capita income increase by $1 \%$, Sichuan tourism demand increases by $1.12 \%$. The test results show that Sichuan tourism demand are elastic to these macroeconomic indicators a, summarily speaking, the of impact macro-economic fluctuation on Sichuan tourism is remarkable.

2) Impulse response analysis

To further analyze the impact of the macroeconomic fluctuation on tourism in Sichuan, we conduct the impulse response test. The test results (Figure 1) shows that the impulse response of Sichuan domestic tourism to Sichuan Consumer Price Index (CPID) reaches the peaks in period one, period three, period five and period seven and stabilize in the lag of 8 years, and the long-term impact proves negative. The response of Sichuan domestic tourism demand to national income per capita (ID) remains moderate overall, and relatively more significant in period two, and the response of Sichuan tourism demand to national per capita income stays positive after period four and long-term. Real interest rate (RD) affects Sichuan tourism demand positively in the first two periods. And the impulse response reaches the positive maximum and after the third period, the impulse response turn negative and reaches the highest negative value in period four, and then tends to be stable after period eight. Generally speaking, real interest rate affects Sichuan domestic tourism demand negatively.

3) Variance decomposition

In order to better understand the variance contribution of the macro explanatory variables to Sichuan domestic tourism demand, we further conduct variance decomposition test on Sichuan domestic tourism demand. Table 1 shows that, in the forecast variance of Sichuan tourism demand, the contribution of per capita income, interest rates and CPI turn to be stabilized in period four, period one and period three respectively. Therefore, we believe that the per capita income affects Sichuan domestic tourism demand with a time lag of four periods, the interest rate with a time lag of one period and consumer price index within a time lag of three periods. It can be observed from Table 1 that in period 10, the knock-on effects of national per capita income, real interest rates and Sichuan consumer price index on Sichuan domestic tourism demand are $48.15 \%, 1.48 \%$ and $28.09 \%$ respectively.

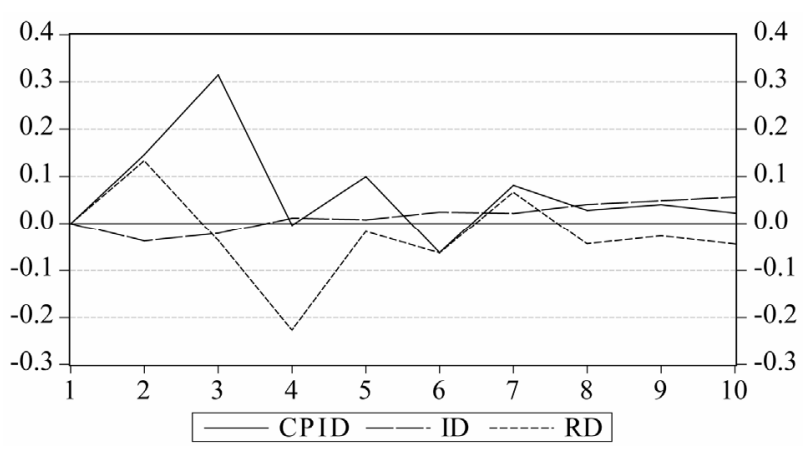

Figure 1. Impulse response analysis. 
Table 1. Variance decomposition (\%).

\begin{tabular}{ccccc}
\hline Period & SC.TI & ID & Int.R & CPI \\
\hline 1 & 100.0000 & 0.000000 & 0.000000 & 0.000000 \\
2 & 47.45186 & 27.71605 & 1.865647 & 22.96644 \\
3 & 20.82278 & 67.44508 & 1.066823 & 10.66532 \\
4 & 16.54933 & 52.09786 & 0.883452 & 30.46936 \\
5 & 15.91501 & 53.93868 & 0.872916 & 29.27339 \\
6 & 17.73483 & 52.15454 & 1.056506 & 29.05412 \\
7 & 17.18329 & 52.24070 & 1.183047 & 29.39296 \\
8 & 18.48157 & 50.72023 & 1.737984 & 29.06022 \\
9 & 18.98392 & 49.95099 & 2.513391 & 28.55170 \\
10 & 20.27002 & 48.15470 & 3.484461 & 28.09082 \\
\hline
\end{tabular}

\section{Conclusion Remarks}

In this paper, we select China's national per capita income, Sichuan consumer price index and real interest rates, which largely represent the macroeconomic situation and business cyclical fluctuations. The study herein found that the changes in these indicators render significant impact on the domestic tourism demand in Sichuan. Particularly speaking, the fluctuations in national per capita income and real interest rate are negatively correlated with Sichuan domestic tourism demand, while national per capita income is positively correlated with it.

Since the macroeconomic indicators that we use in this paper have different time lag to and impact on Sichuan tourism, Sichuan tourism authorities should take such differences into their policy making to weaken the possible "overkill" impact. From the results of the forecast variance decomposition, the per capita income is the best indicator as weathercock and intermediate target for Si- chuan domestic tourism demand, which is also consistent with the theoretical analysis in this paper. And according to the study, the consumer price index also deserves authority's attention for its importance in Sichuan tourism regulation and promotion. The regression analysis result shows the interest rate elasticity of Sichuan domestic tourism demand is considerable comparatively, so the interest rate is well of availability as a control tool. However, for the local government, Sichuan consumer price index as a regulatory agent proves even more maneuverable and efficient than national per capita income and interest rates.

\section{REFERENCES}

[1] M. Lonhmann, “New Demand Factors in Tourism,” European Tourism Forum, Budapest, 15 October 2004.

[2] Q. Guo, "Co-Integration Analysis of Leisure Demand and Economy Growth," Recent Advance in Statistics Application and Related Areas: Proceedings of IIASS Conference, Vol. 1, 2009, pp. 2085-2089.

[3] Z. Gu, "The Relationship between Interest Rate and Tourism Activities,” International Journal of Hospitality Management, Vol. 14. 1995, pp. 239-243. doi:10.1016/0278-4319(95)00012-7

[4] G. K. Turnbull, "Location, Housing, and Leisure Demand under Local Employment,” Land Economics, Vol. 68, No. 1, 1992, pp. 62-71. doi:10.2307/3146743

[5] J. D. Owen, “The Demand for Leisure," The Journal of Political Economy, Vol. 79, No. 1, 1971, pp. 56-76. doi:10.1086/259724

[6] L. Philips, “The Demand for Leisure and Money,” Econometrica, Vol. 46, No. 5, 1978, pp. 1025-1043. doi:10.2307/1911434

[7] Y. G. Zhu, M. H. Wu and C. Li, "Empirical Research on Nanjing Residents Travel Demand,” Social Scientists, Vol. 6, 2007, pp. 120-123. 